\title{
ULTRASONOGRAPHY, COMPUTED TOMOGRAPHY AND HISTOPATHOLOGICAL EVALUATION OF THE USE OF PLATELETS RICHED PLASMA (PRP) AND INSULIN ON LONG BONE FRACTURE HEALING IN RATS
}

\author{
FATHY, M.Z. ${ }^{1}$; NESREEN M. SAFWAT ${ }^{2}$ and RAGAB, G.A ${ }^{1}$ \\ ${ }^{1}$ Surgery, Anesthesiology and Radiology Department, Faculty of Veterinary Medicine, Beni-Suef Univ., \\ Beni Suef 62511, Egypt. \\ ${ }^{2}$ Pathology Department, Faculty of Veterinary Medicine, Beni-Suef Univ., Beni Suef 62511, Egypt.
}

Received: 11 February 2019; Accepted: 11 March 2019

\begin{abstract}
To evaluate the effect of PRP and insulin on promotion of healing rate in experimental animal's long bone fracture. The current study was conducted with 27 white albino rats weighing between 150 and 200 gm. These animals were divided into three groups (nine rats in each). The experiment consisted of two stages: the first stage, involved the surgical induction of complete tibial fracture under the effect of general anesthesia. The second stages, cast was applied only in G1, while in G2, cast was applied after injection of insulin in the site of fracture, as well as cast was applied after inject PRP at the site of fracture in G3. ultrasonography, computed tomography and histopathology were used to evaluate the rate of bone fracture healing for each group. The result showed that, the echogenicity change at the fracture rapidly in PRP group followed by insulin group and slowly in control group. The bone density was increased rapidly and high in PRP group followed by insulin group and finally the bone density is low in control group and the histopathological evaluation confirms these results. In conclusion, using of PRP has a greater useful effect in promoting bone fracture healing rate and tissue proliferation than insulin.
\end{abstract}

Key words: Bone Fracture, Rats, Platelets Riched Plasma, Insulin, Ultrasound, C.T, Pathology.

\section{INTRODUCTION}

Fracture healing is a compound process that includes different regulators and biochemical, hormonal and growth factors which interact with the healing process (Einhorn, 1995; Wilkens et al., 2003 and Say et al., 2014). The fracture healing process should be passed via three stages, they includes deposition, resorption and remodeling (Kalfas, 2001). Fracture healing is looking as a tardily operation that causing long immovable periods for complete healing, and delayed fibrosis and/ or nonunion healings are the most subsequent problems that face the surgeon and the animals (Bostrom and Camacho, 1998 and Bouxsein et al., 2001).

The biology of bone, ligaments, and tendons healing that directed us to investigate numerous products that promote the fracture healing, using of these products is depend on stimulation of growth factors to fast the healing of bone and soft tissues. Insulin

Corresponding author: FATHY, M.Z. E-mail address: mzfhussein83@gmail.com

Present address: Surgery, Anesthesiology and Radiology Department, Faculty of Veterinary Medicine, Beni-Suef Univ., Beni Suef 62511, Egypt. and Platelet rich plasma (PRP) are examples of this product (Foster et al., 2009). PRP is defined as higher plasma concentration of platelet than platelet concentration found in whole blood (Foster et al., 2009; Wroblewski et al., 2010).

In fracture healing, platelets play as source of growth factors that promot bone growth (Bolander, 1992 and Thiede et al., 1993). At the fracture site, platelets release about fifteen growth factors that have the greatest potential for fracture repair because both chondrocytes and osteoblast are enriched with receptors TGF- $\beta 1$. (Shantaram, 2016).

There is another product that has the ability to accelerate the healing process is insulin which has an anabolic role in bone (Graves, et al., 2011).

Bone is a unique organ in the body because its scarless regenerative capacity (Glowacki, 1998). Repair of fractures by callus production occurs in four overlapping phases (Einhorn, 1995; Einhorn, 1998; Mandracchia et al., 2001; Hadjiargyrou et al., 2002 and Gerstenfeld et al., 2003). Following damage to the musculoskeletal system, disruption of blood vessels leads to activation of the coagulation cascade and formation of a hematoma, which encloses the fracture area. Removal of the hematoma 
significantly attenuates repair, and transplantation of the hematoma produces new bone, consistent with the angiogenic activity of the hematoma (Mizuno et al. 1990; Grundnes, and Reikeras, 1993; Street et al., 2000 and Street et al., 2001). Inflammatory cells, fibroblasts, and stem cells are recruited to the site, and new blood vessels are formed from pre-existing ones (i.e. angiogenesis). The inflammatory response is associated with pain, heat, swelling, and the release of several growth factors and cytokines that have important roles in repair (Einhorn, 1995; Hauser et al., 1997; Barnes et al., 1999;
Mandracchia et al., 2001 and Gerstenfeld et al., 2003).

Initially, granulation tissue forms at the ends of bones, gradually being replaced by fibrocartilage, in a manner seemingly related to the vascular pattern (Trueta, 1963). Meanwhile, the periosteum undergoes direct bone formation, or intramembranous ossification, to create an external callus. Subsequently, the internal callus becomes mineralized with calcium hydroxyapatite, to form a hard callus. In the final, remodeling phase of bone regeneration.

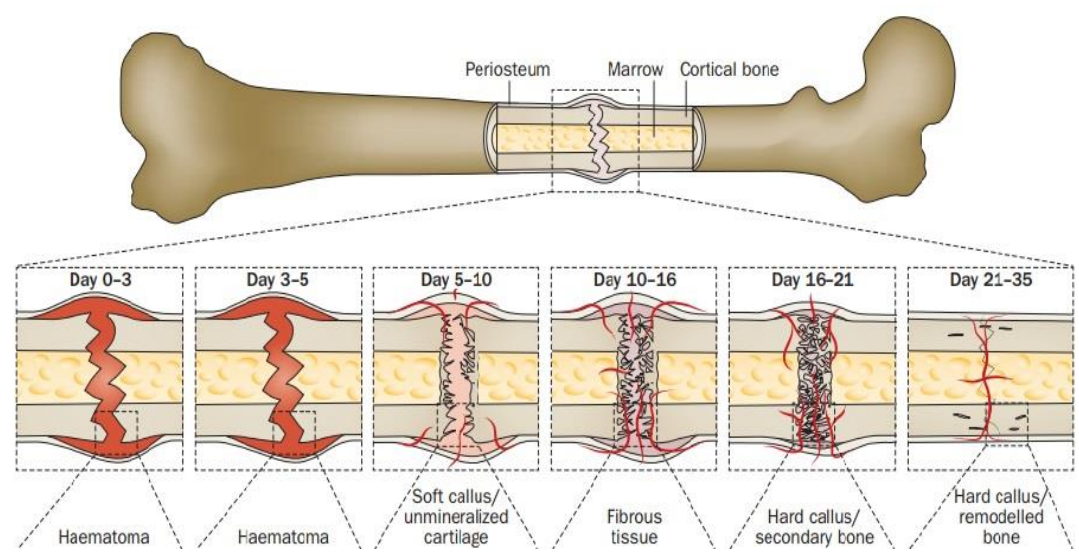

Fracture healing: mechanisms and interventions Einhorn and Gerstenfeld (2015).

The aim of this study is to evaluate the local effect of PRP and insulin on bone healing and to assess the fracture healing process by using ultrasonographic, Computed Tomographic and histopathological techniques to know the effect of these substances on enhancing and/or promotion of bone fracture healing.

\section{MATERIALS AND METHODS}

\section{Animals}

This study was conducted on 27 white albino rats weighing between 150 and $200 \mathrm{gm}$. These animals were divided into three groups (nine rats in each group).

\section{The experiment}

The animals were anaesthetized by using $0.1 \mathrm{ml}$ of anesthetic mixture $(10 \mathrm{mg} / \mathrm{kg}$ xylazine hydrochloride and $100 \mathrm{mg} / \mathrm{kg}$ ketamine $\mathrm{HCl}$.) intra-peritoneal injection. The experiment was consisted of two steps: the first step includes surgical induction of complete tibial fracture at the distal third (Fig. 1). The second step using external fixation only in control group (GI) (Fig. 2). While in the second group (GII), $0.2 \mathrm{ml}$ of freshly prepared platelet Richet plasma (PRP) was injected at the fracture site then a cast was applied (Fig. 3). In group (III), inject $0.2 \mathrm{ml}$ of insulin (NovoRapid $^{\circledR}$ Penfill, $100 \mathrm{U} / \mathrm{ml}$, Egyptian Drug Trading Company) at the fracture site was performed and then a cast was applied (Fig. 4). The next stage of the experiment was performed to evaluate the different changes of bone fracture healing and effect of different treatments in different groups at one, two, and four weeks interval by using of the following techniques:

\section{1-Ultrasonography:}

Ultrasonographic examination was done at one, two and four weeks by using Mindray veterinary ultrasound device 5000 connected with linear multifrequency transducer 5.0-10.0 MHz. The examined area was shaved and ultrasound coupling gel was applied. The prepared areas were scanned in sagittal plane to early and easily detection any changes at the fracture site by $10.0 \mathrm{MHz}$.

\section{2 - Computed Tomography (CT):}

This method was done at one, two and four weeks to evaluate the pattern of bone healing in different groups by determination the bone density at the fracture site by using CT (Go Now, 16 slices, Siemens, Germany). 


\section{3 - Histopathology}

Both gross and microscopic pathological evaluation of experimentally induced simple aseptic tibial fracture of albino rats were done after euthanasia of animals according to the Local Experimental Animal Care Committee and approval of the ethics of the Beni- Suef university committee.

The gross alterations were photographed and recorded by the use of digital cam (Nikon Coolpix L 340, 28x optical zoom wide20.2 Megapixels. NikonCorp, Japan) after collection of legs of each rat groups at time of one week and two weeks post fracture after gross examination for periosteal, endosteal reactivity and nature of callus.

Soft tissues that covering fractured bones were removed for obtaining only tibial bone samples then preserved in $10 \%$ neutral buffered formalin for 3 days. After fixation process, all specimens were washed from formalin by running tap water for about 4 hours, then immersed in a decalcifying agent of $17 \%$ EDTA disodium solution (Ethylenediamine tetra-Acetic acid disodium salt B.P.93®: El Nasr

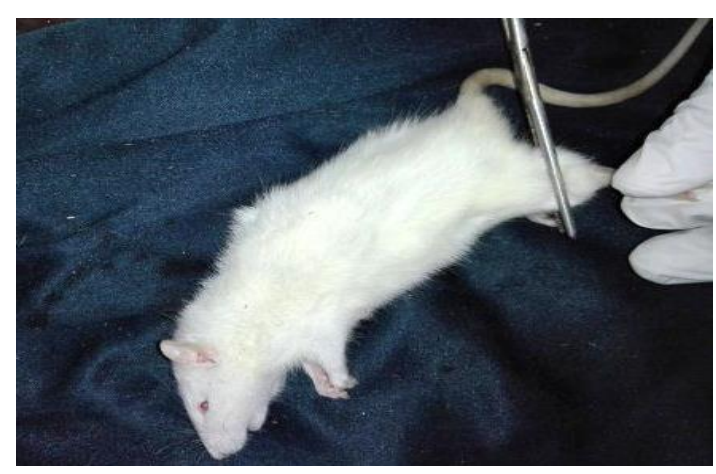

Fig. (1) Experimental induction of tibial fracture

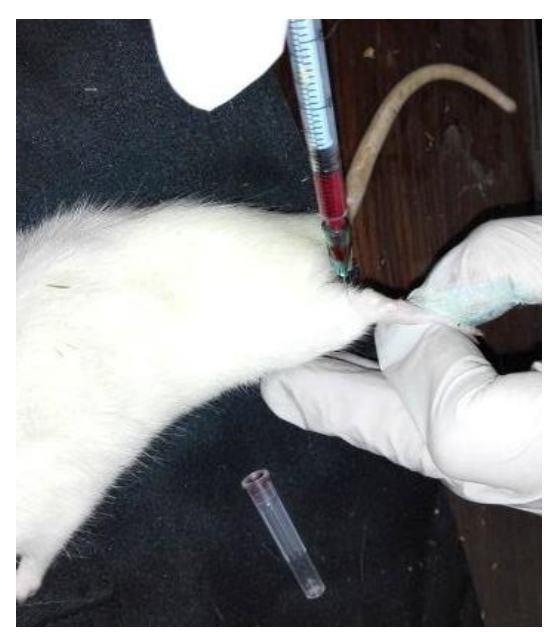

Fig. (3) Local application of PRP pharmaceutical chemical, Egypt) for one month during which the specimens were inspected weekly for signs of complete decalcification appeared (Shibata et al., 2000).

After complete decalcification, the specimens were washed in running tap water for 6 hours, then dehydrated in ascending grades of ethyl alcohol (70 $\%, 80 \%, 90 \%$ and $96 \%$ ) (Absolute I, Absolute II and Absolute III), cleared in xylene (xylene I, xylene II and xylene III) and embedded in soft paraffin (paraffin I, paraffin II and paraffin III) then blocked in hard paraffin wax, sectioned 5-7 $\mu$ and stained with routinely Hematoxylin and Eosin according to (Bancroft and Gamble, 2008 and Fathy et al., 2018). The stained sections were imaged by use Leica Full HD Camera that fixed on Leica DM2500 - Leica DF290 microscope.

\section{4 - Image analysis:}

This technique was done to compare the diameter of callus formation between different three groups by using image j software (http://rsb.info.nih.gov/ij/) (Fig. 5).

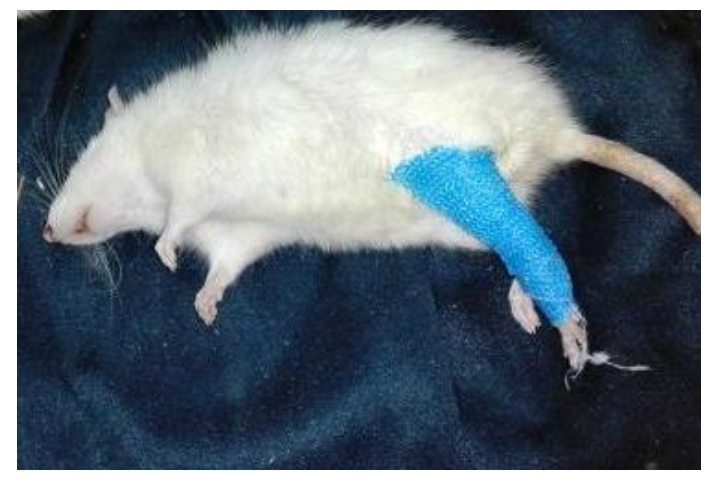

Fig. (2) Application of cast

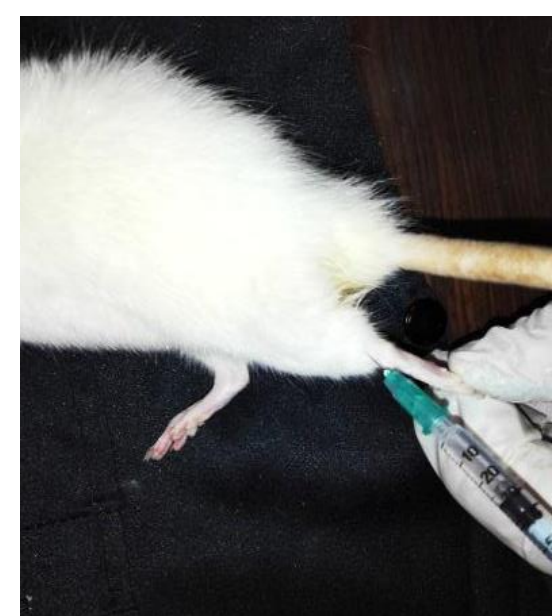

Fig. (4) Local application of insulin 

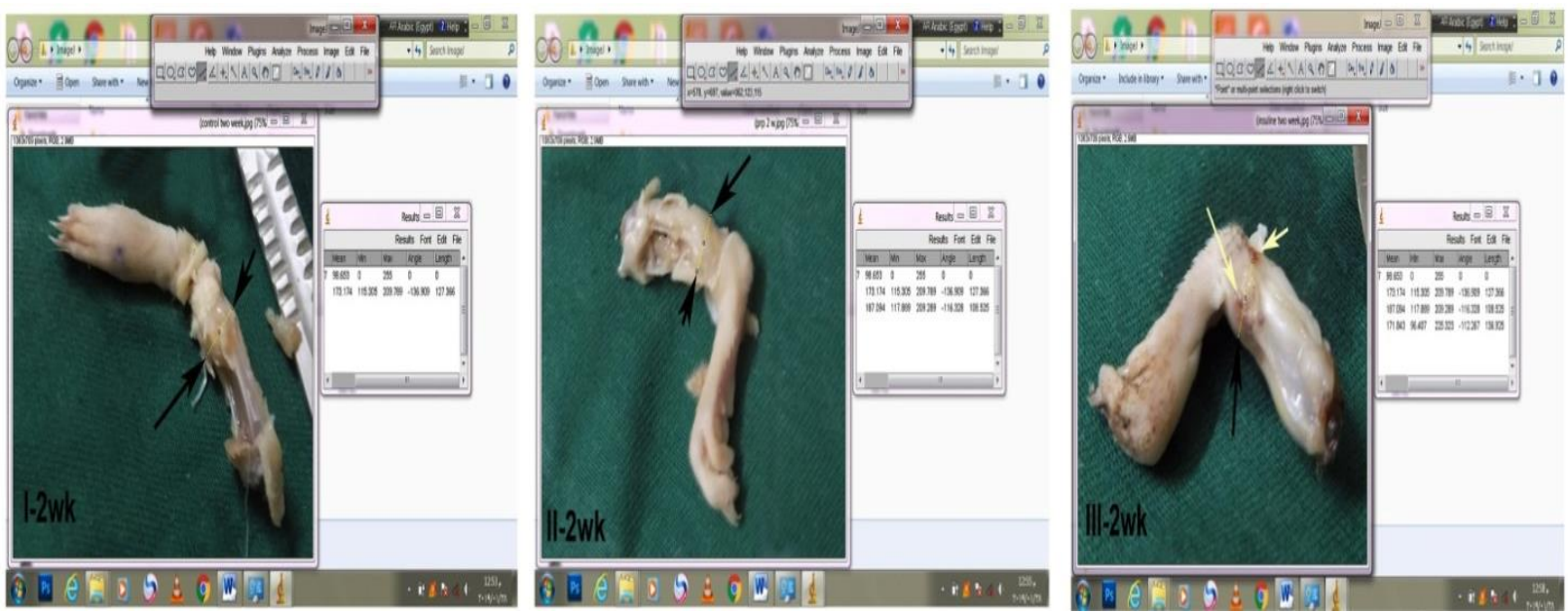

Fig. (5): Showing the image analysis, the length between two black arrows in control group is 127 while in PRP injected group is 108 but in insulin injected group is 136

\section{RESULTS}

No death or complications to the rats were observed during the entire duration of the study. Animals were allowed to walk within their cages untill the stage of euthanasia at week 4. Upon resection observation of the fractured tibia, no evidence of inflammation or infection was present at the fractured site.

The normal appearance of the healthy bone ultrasonography is a hyper-echoic line and the normal bone density by CT measured by 1352 . (Fig. $6)$.

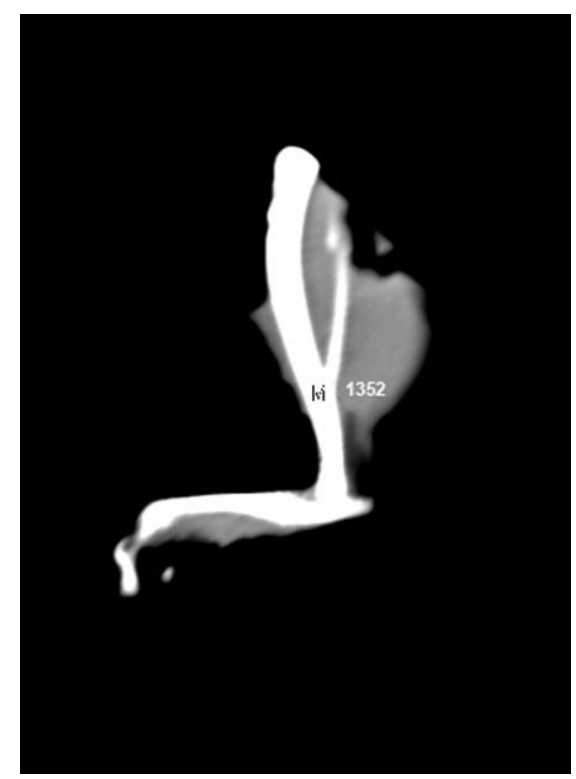

Fig. (6): CT showing the normal bone density is 1352 .

In group (I), ultrasonographically, at first week, the fractured site appeared as a hypo-echoic area (Fig. 7) while at two weeks, the fractured site has small hypo-echoic area and the fractured end as a hyperechoic points which are near to each other (Fig. 8) but at four weeks, the fracture gap appeared as hyper-echoic line which connect the part of two ends of fractured ends (Fig. 9).
Computed tomography, at first week, the fractured site appeared as a hypo-dense area and the bone density is 213 (Fig. 10) while at two weeks, increase in dense at the fractured site and the bone density is 353 (Fig. 11). At four weeks, the fracture gap was appeared as hyper-dense area and the bone density is 577 (Fig. 12). 


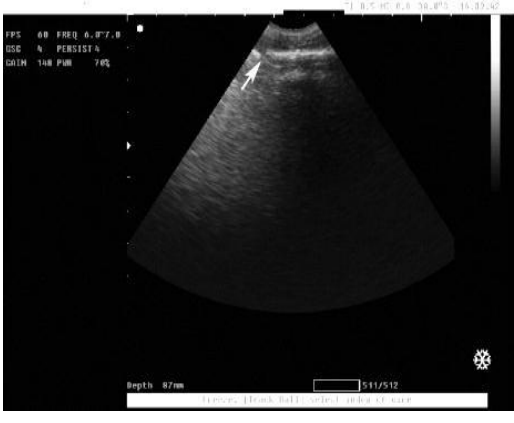

Fig. (7)

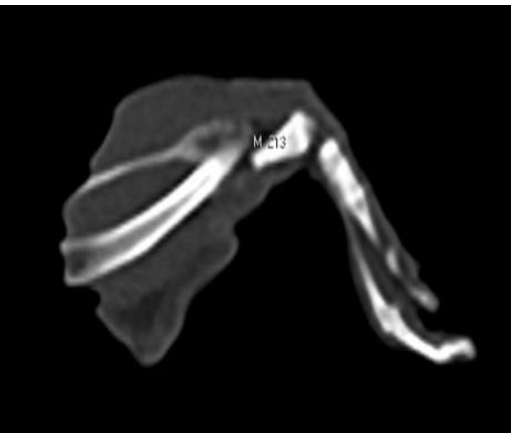

Fig. (10)

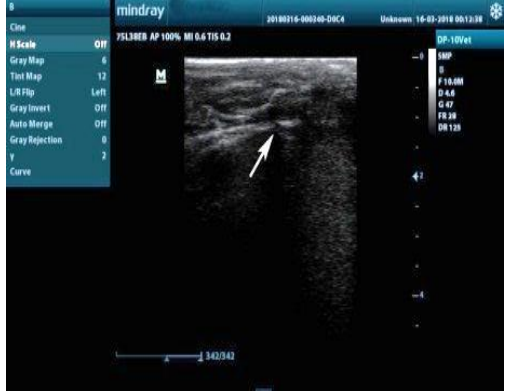

Fig. (8)

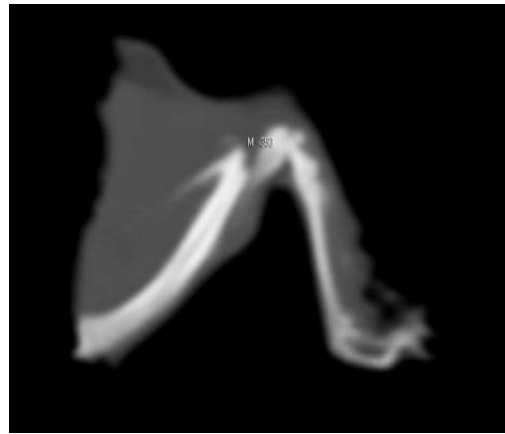

Fig. (11)

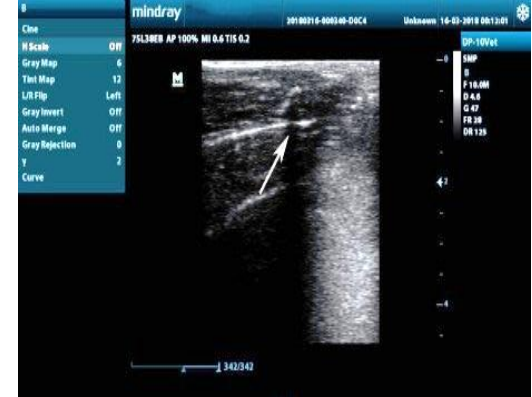

Fig. (9)

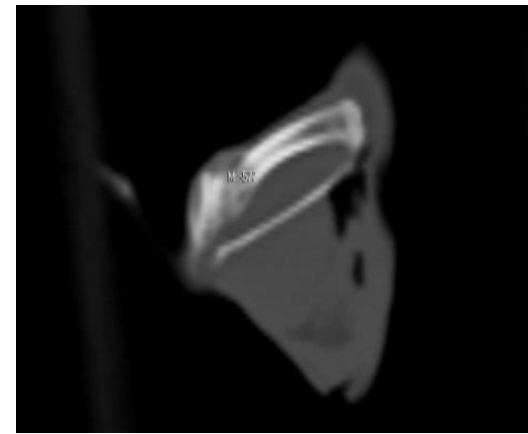

Fig. (12)

Fig. 7: Ultrasonogram showing the fractured site appeared as a hypo-echoic area (white arrow)

Fig. 8: Ultrasonogram showing the fractured site has small hypo-echoic area and the fractured end as hyperechoic points which are near to each other (white arrow).

Fig. 9: Ultrasonogram showing the fracture gap appeared as hyper-echoic line which connect the two ends of fracture

Fig. 10: CT showing the fractured site appeared as a hypo-dense area and the bone density is 213 .

Fig. 11: CT showing increase in dense at the fractured site and the bone density is 353 .

Fig. 12: CT showing the fracture gap was appeared as hyper-dense area and the bone density is 577 .

In group (II), Ultrasonographically, at first week, the fractured site appeared as a hypo-echoic area due to presence of soft callus (Fig. 13). At two weeks, increase of echogenicity at the fracture site due to presence of hyper-echoic denote in fracture gap due to presence of initial stage of hard callus (Fig. 14). At four weeks, presences of hyper-echoic line fill in the fracture gap and this is attributed to hard callus formation (Fig. 15).
Computed tomography, at first week, the fractured site appeared as a hypo-dense area and the bone density is 779 (Fig. 16) while at two weeks, increase in dense at the fractured gap and the bone density is 1081 (Fig. 17). At four weeks, the fracture gap was appeared as hyper-dense area and the bone density is 1230 (Fig. 18). 


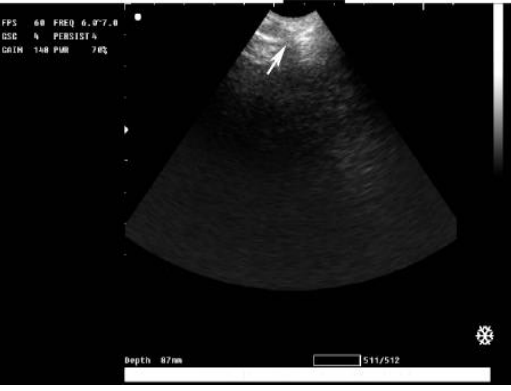

Fig. (13)

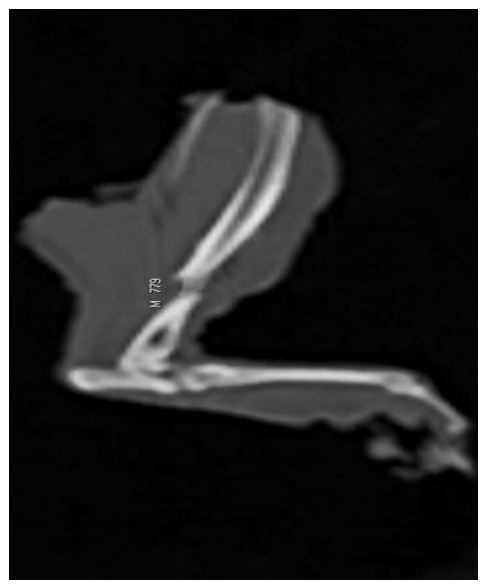

Fig. (16)

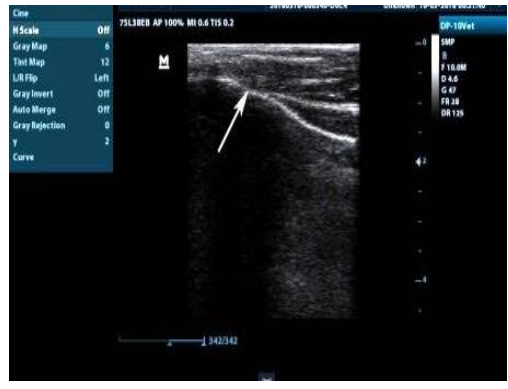

Fig. (14)

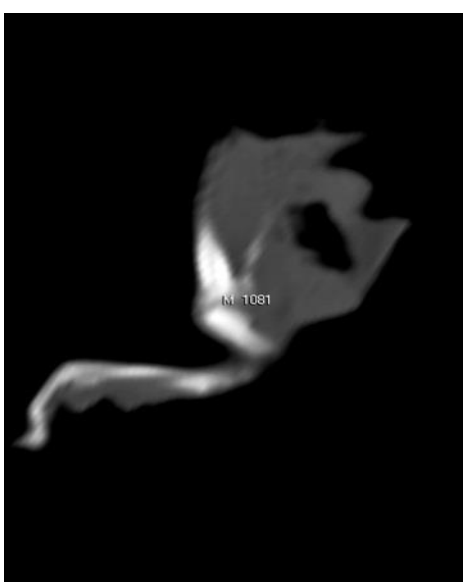

Fig. (17)

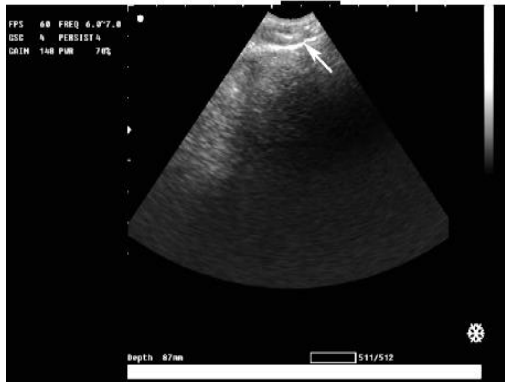

Fig. (15)

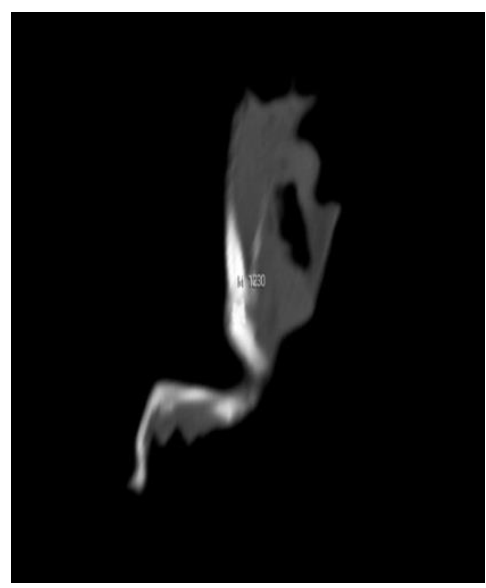

Fig. (18)

Fig. 13: Ultrasonogram showing the fractured site appeared as a hypo-echoic area due to presence of soft callus (white arrow)

Fig. 14: Ultrasonogram showing increase of echogenicity at the fracture site due to presence of hyper-echoic denote in fracture gap due to presence of initial stage of hard callus (white arrow)

Fig. 15: Ultrasonogram showing presences of hyper-echoic line fill in the fracture gap and this is attributed to hard callus formation

Fig. 16: CT showing the fractured site appeared as a hypo-dense area and the bone density is 779

Fig.17: CT showing increase in dense at the fractured site and the bone density is 1081 .

Fig. 18: CT showing the fracture gap was appeared as hyper-dense area and the bone density is 1230

In group (III), at first week, the fractured site appeared ultrasonographically as a hypo-echoic area (Fig. 19) while at two weeks, increase of echogenicity at the fracture site due to initial presence of soft callus (Fig. 20). At four weeks, presences of hyper-echoic denote in the fracture gap and this is attributed to initial stage of hard callus (Fig. 21).
Computed tomography, at first week, the fractured site appeared as a hypo-dense area and the bone density is 459 (Fig. 22) while at two weeks, increase in dense at the fractured gap and the bone density is 824 (Fig. 23). At four weeks, the fracture gap was appeared as hyper-dense area and the bone density is 990 (Fig. 24). 


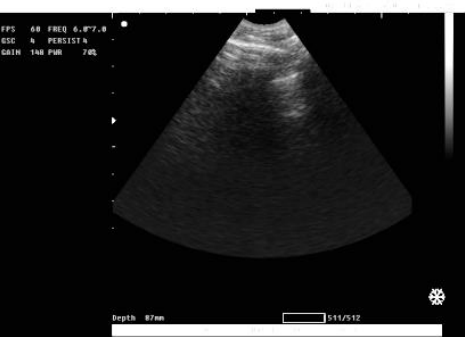

Fig. (19)

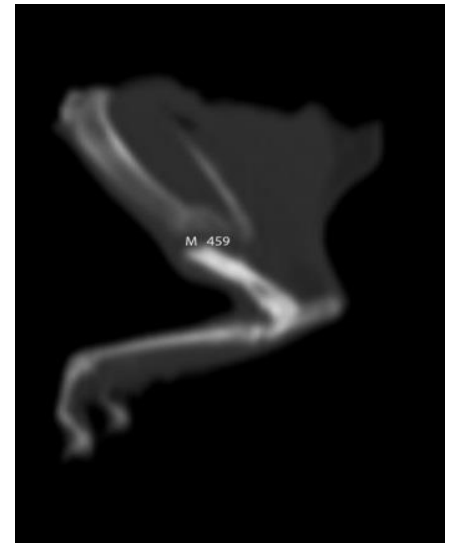

Fig. (22)

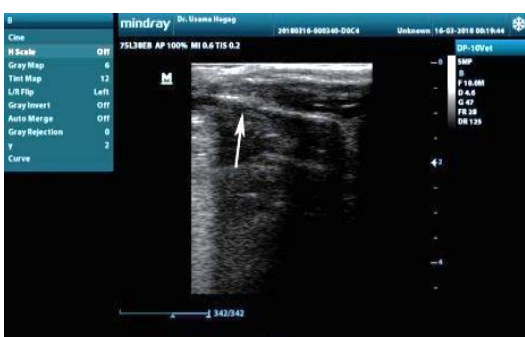

Fig. (20)

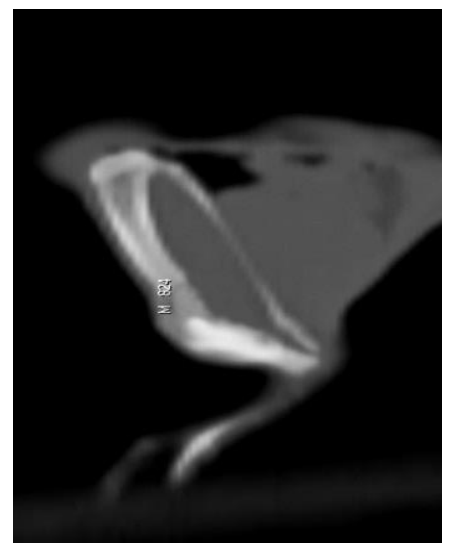

Fig. (23)

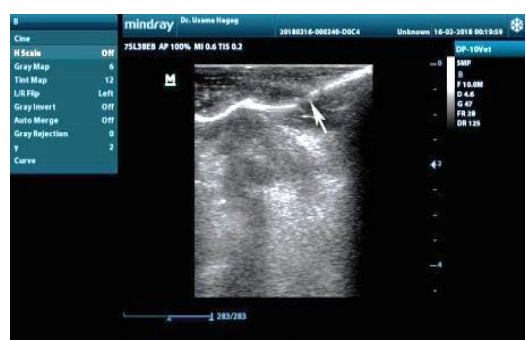

Fig. (21)

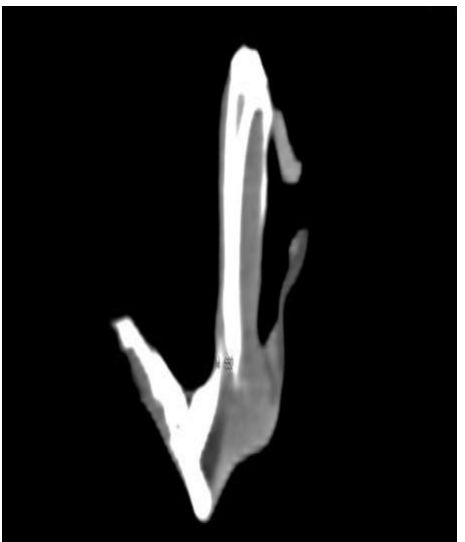

Fig. (24)

Fig. 19: Ultrasonogram showing the fractured site appeared as a hypo-echoic area (white arrow)

Fig. 20: Ultrasonogram showing increase of echogenicity at the fracture site due to presence of soft callus (white arrow)

Fig. 21: Ultrasonogram showing presences of hyper-echoic denote in the fracture gap and this is attributed to initial stage of hard callus

Fig. 22: CT showing the fractured site appeared as a hypo-dense area and the bone density is 459

Fig. 23: CT showing increase in dense at the fractured site and the bone density is 824 .

Fig. 24: CT showing the fracture gap was appeared as hyper-dense area and the bone density is 990 .

The gross pathological alterations of the fracture site were recorded at one week (1wk) and two weeks ( 2 wk) for each group (I-Control group; $0.2 \mathrm{ml}$ normal saline / one dose immediately after fracture induction), (II-Platelet Rich Plasma PRP group; $0.2 \mathrm{ml}$ PRP / one dose immediately after fracture induction), and (III-Insulin group; 0.2 $\mathrm{ml}$ insulin / one dose immediately after fracture induction) Plate (1 and 2).
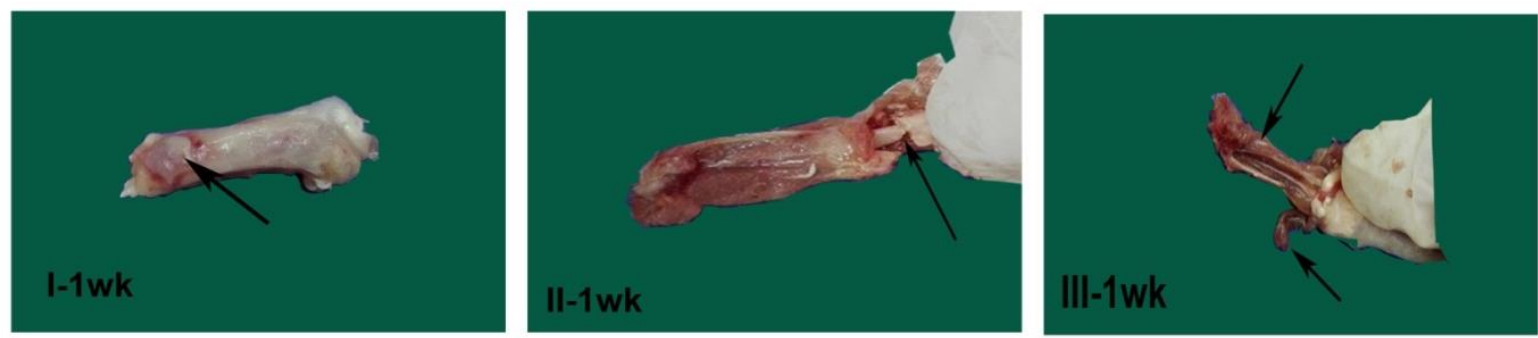

\section{Plate (1)}
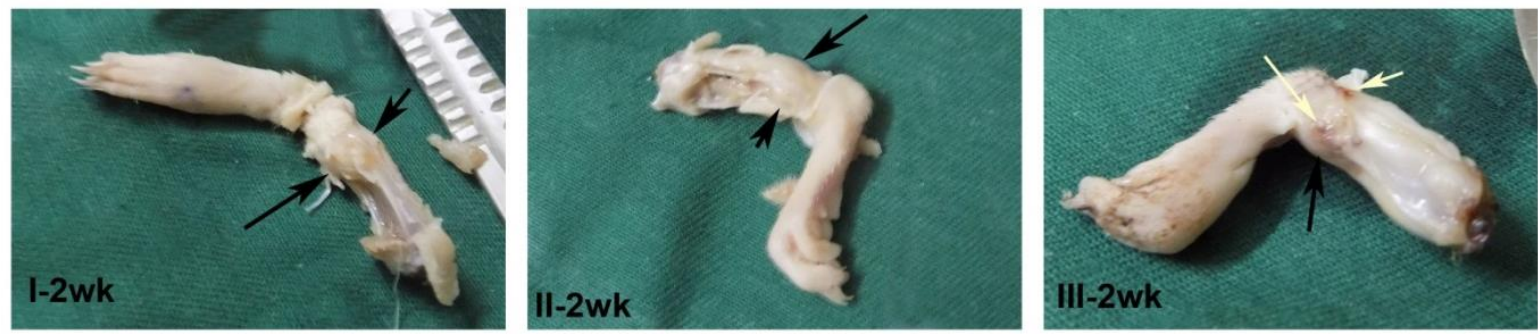

Plate (2) 
(Plate, 1) Fig. (I-1wk): Photograph of rat tibia of control group showing inflammatory red zone at fracture site (black arrow), Fig. (II-1wk): Photograph of rat tibia of PRP group showing fracture site (black arrow) while the surrounding musculature constitute minimal inflammatory reaction, Fig. (III-1wk): Photograph of rat tibia of insulin group showing sever inflammatory reaction in muscles either far from or near to surrounding fracture site (two black arrows).

(Plate, 2) Fig. (I-2wk): Photograph of rat tibia of control group showing beginning of formation of hard callus at fracture site (two black arrows), Fig. (II-2wk): Photograph of rat tibia of PRP group showing hard callus formation at the fracture site (black arrow), Fig. (III-2wk): Photograph of rat tibia of insulin group showing callus formation (black arrow) associated with congested blood capillaries (two yellow arrows) surrounding fracture site.

When the length of hard callous determined by image analyzer software of gross images taken from tibial bone, two weeks post fracture revealed that in control group, the callous length was 127, while in PRP injected group was much more lesser than control one 108 even lesser than insulin injected group which was 136 .

The histopathological examination of the fracture site of different groups revealed that:

In control group, in $1^{\text {st }}$ week post fracture, the fracture gap (FG) was filled with granulation tissue which characterized by loose interlacing fibrous connective tissue which is rich in blood capillaries entangling in it lymphocytes representing the end of the inflammatory phase of the bone fracture healing subsequently after hematoma formation (Fig. 25). While bone fragments (BF) still present near to the fracture gap next to it the bone marrow of the bone (BM). In $2^{\text {nd }}$ week post fracture, the blood capillaries were absent, while the fibrous connective tissue become much more abundant and compact filling the fracture gap (FG) as the beginning of the proliferative phase of bone fracture healing (Fig. 26). The neighbors bone beside the fracture gap showing activated osteoblasts penetrates toward the fracture site (Fig. 27).

In PRP injected group, by examination of the fracture site at the $1^{\text {st }}$ week, the fracture site showed that an early proliferation of fibrous connective tissue filling the fracture gap with minimal numbers of blood capillaries and leucocytes (Fig. 28). The end of inflammatory phase and the beginning of the proliferative phase of fracture bone healing.

In insulin injected group, the histopathological examination of the fracture site in $2^{\text {nd }}$ week post fracture revealed that connective tissue rich in blood capillaries and inflammatory cells, while the bony matrix showing activation of osteoblasts (Fig. 29 and Fig. 30). As an inflammatory phase of bone fracture healing.

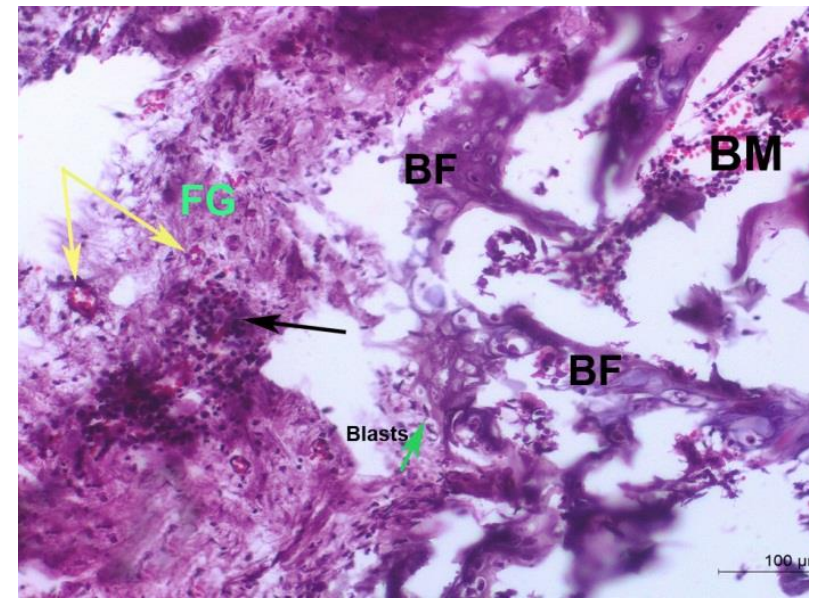

Fig. (25): Photomicrograph of rat tibia of control group post fracture by one week showing granulation tissue filling fracture gap (FG), rich by blood capillaries (two yellow arrows), and entangling in it lymphocytes representing the end of the inflammatory phase of the fracture (black arrow), while bone fragment (BF) Bone marrow (BM) (H\&E; Bar= 100 $\mu \mathrm{m})$.
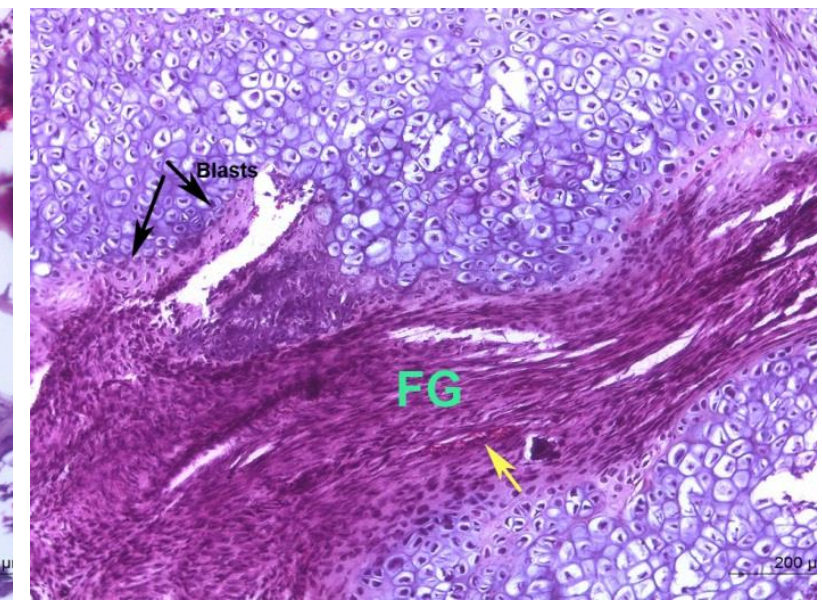

Fig. (26): Photomicrograph of rat tibia of control group post fracture by two weeks showing proliferative connective tissue filling fracture gap (FG), with minimal numbers of blood capillaries (yellow arrow), and activated osteoblasts (two black arrows) (H\&E; Bar $=200 \mu \mathrm{m})$. 


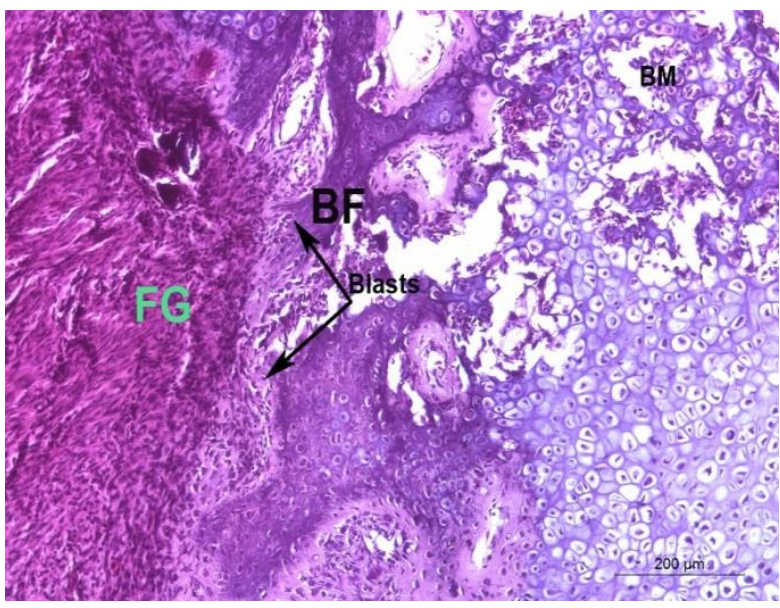

Fig. (27): Photomicrograph of a higher magnification of the previous picture showing compact connective tissue filling fracture gap (FG), and activated osteoblasts (two black arrows) (H\&E; Bar= $200 \mu \mathrm{m})$.

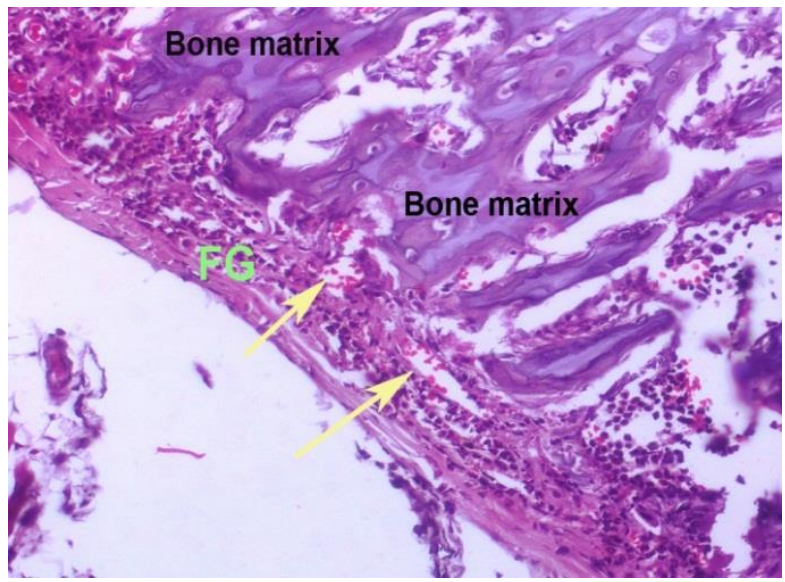

Fig. (29): Photomicrograph of rat tibia of insulin group post fracture by two weeks showing granulation tissue rich in blood capillaries (two yellow arrows) filling fracture gap (FG), with (H\&E; Bar= $200 \mu \mathrm{m})$.

\section{DISCUSSION}

The strategy of this study was designed to identify and to evaluate the local effect of PRP and insulin in acceleration of bone regeneration and healing at the fractured sites of long bone using an experimentally laboratory animal model.

PRP stimulate and promote the healing rat of bone fractures. This finding was in agreement with that given by Anitua et al. (2006) and Castillo-Cardiel et al. (2017) who mentioned that the PRP therapeutic is a relatively new biotechnology that used to accelerate the healing of soft and hard tissues which applied in multiple aspects of medicine like (orthopedics and maxillofacial surgery).

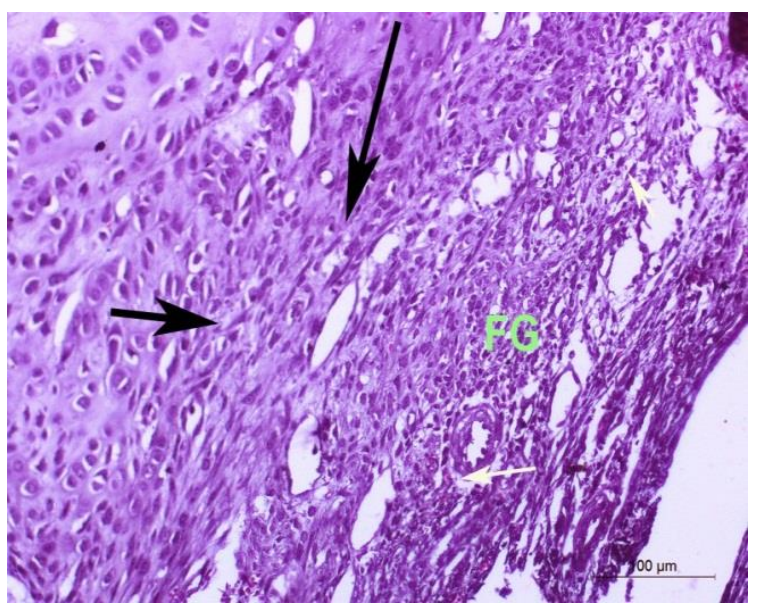

Fig. (28): Photomicrograph of rat tibia of PRP group post fracture by one week showing proliferative connective tissue filling fracture gap (FG), with minimal numbers of blood capillaries (yellow arrow), and activated osteoblasts (two black arrows) (H\&E; Bar= $100 \mu \mathrm{m})$.

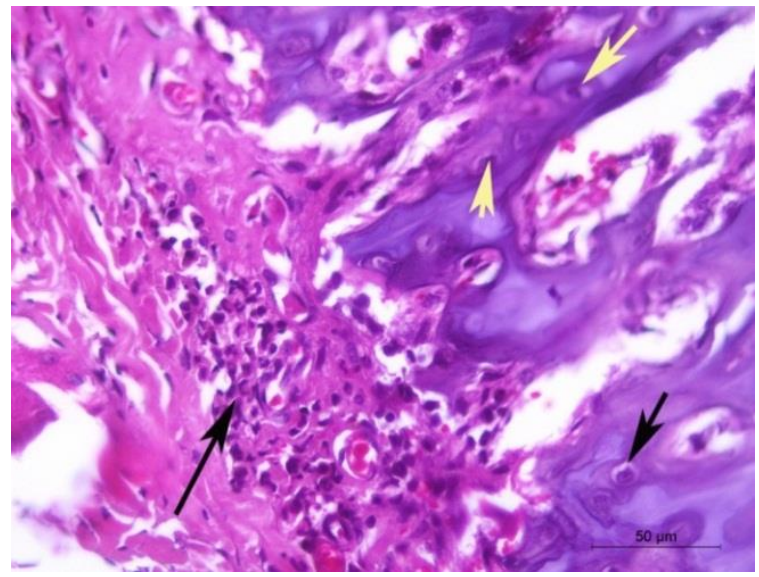

Fig. (30): Photomicrograph of rat tibia of insulin group post fracture by two weeks showing inflammatory cells (black arrow) filling fracture gap (FG), with high numbers of blood capillaries, and activated osteoblasts (two yellow arrows) (H,E; Bar= $50 \mu \mathrm{m})$.

In this study, PRP technique is simple low cost technique and does not causes any harmful effect to the animal, reducing the time for fracture healing. These findings are in agreement with that given by (Castillo-Cardiel et al., 2017).

Application of PRP was associated with lower healing period and less postoperative infection and pain. This result was in correlation with (Ghaffarpasand et al., 2016). Because the PRP release interleukin 1 (IL-1) that play an important role in the regulation of immune and inflammatory responses to infections.

This study detects the local application of the autologous PRP which considered as an effective 
method for stimulation bone regeneration (BR) and noticeable acceleration at the fracture site without complications. This evidence was in coincide with (Castillo-Cardiel et al., 2017).

By determination of both ultrasonographic echogenicity and computed tomography density and bone density at $1^{\text {st }}, 2^{\text {nd }}$ and $4^{\text {th }}$ weeks' time intervals of PRP group and insulin group in comparison to the normal bone density which determined before fracture induction. The PRP group becomes much more similar to the normal bone density at $4^{\text {th }}$ week or at the end of the experiment. While insulin group, the density not reach or approximate the normal bone density, (Ultrasonographic echogenicity computed tomography bone showed significant differences favoring the two experimental group than the control group) and these findings agreed with (Castillo-Cardiel et al., 2017).

A good effect of PRP on bone regeneration (BR) and its clinical and surgical importance and it has many properties include autologous product, induces angiogenesis and promotes osteo-integration and cell proliferation. Also it has a hemostatic and lymphatic bioseal which decreasing post-operative drainage and edema (Anitua et al., 2016 and Pocaterra et al., 2016) this way improving BR and shortening the time for recovery.

Subsequent to an injury, capillaries invading a fibrin clot are one of the most important cellular components of early granulation tissue because they deliver nutrients, inflammatory cells, and oxygen to the wound site, on the other hand, the lack of angiogenesis can result in impaired wound healing (Lingen, 2001). Also Battegay, (1995) mentioned that new blood vessel growth is required for the removal of necrotic tissue and considered starting point for the repair process.

It is possible that the local insulin injections promote wound healing by stimulating the expression of vascular endothelial growth factor VEGF, which promotes endothelial cell proliferation, also increases the permeability of capillaries thus promoting the formation of new blood vessels (Puddu et al., 2016).

One popular theory was that the cells were differentiated from the endothelial cells of the nearby blood vessels, whereas others believed that the cells came from the peripheral blood or resting wandering cells.

The PRP have cytokines and growth factors important to improve the vascularization and tissue proliferation (Hee et al., 2003 and Coetzee et al., 2005).
Transforming growth factor- $\beta$ (TGF- $\beta$ ) mainly comes from blood platelets, it can promote the chemotaxis, migration, proliferation, and differentiation of cells and the formation of granulation tissue by extracellular accretion and secretion, essential factors of wound healing. (Kryger et al., 2007 and. Koskela et al., 2016). IL-1 makes the generation of cells, neutrophils and lymphocytes possible by chemotaxis. It stimulates the fibroblasts to produce collagen and controls the formation of scarring tissue, playing acrucial role in wound healing.

Platelet-rich plasma contains up to 8 times the concentration of platelets found in whole blood. The fact that PRP contains several different growth factors, present in physicological proportions, is an appealing benefit compared to isolated growth factors (Sánchez et al., 2007; Creaney and Hamilton 2008 and Hammond et al., 2009).

The lower degrees of inflammation and angiogenesis in the study group was caused by the proven effect of PRP on the increased expression of the matrix degrading enzymes in addition to the increased cell proliferation and collagen production at tendon cells, resulting in accelerated remodeling of the injured tendon (Anitua et al., 2005 and De Mos et al., 2008).

Additionally, Hammond et al. (2009) reported improvement and recovery from muscle strain with limitation of the inflammation in a rat muscle injury model as early as possible, 3 days after the injection.

Local Insulin application improve chondrogenesis and cellular proliferation within the first 4 weeks. This finding in correlation with (Gandhi et al., 2005; Graves et al., 2011 and Da-Wei Wang et al., 2013) who suggests that insulin treatment following fracture is accompanied with increasing of VEGF biosynthesis in the fractured tissues, which may be responsible for the improved bone healing.

Local application of insulin has the important effect in accelerate early and late stages of fracture healing. This finding is coincide with (Gandhi et al., 2005) who mentioned that the various stages of fracture healing could be accelerated with the effect of expression of three soluble factors (proinflammatory cytokines, the TGF-h superfamily and angiogenic factors) insulin that play a critical role in modulating the repair process. Local low-dose insulin acts independently of blood sugar metabolism in promoting wound healing, and it plays an important regulatory role in the course of regeneration of cell factors, growth factors and inflammatory reactions of multiple epithelia. Also, it could markedly promote wound healing and the survival of transplanted flaps after operation for deep burns, and this is probably associated with the 
stimulation of higher expression levels of HSP-90, VEGF, TGF- $\beta$ and IL-1, which nevertheless, exert little influence on systemic blood glucose (Ming et al., 2016).

Whether the insulin is injected via subcutaneous, infiltration or intravenous injection, its actions depend on its ability to regulate the blood sugar metabolism. Insulin is a polypeptide with a short half-life in vivo. It may be decomposed by proteases in tissue when directly applied to wounds, and therefore reapplications are needed for treatment. The problem of how to continually release insulin in an effective manner to promote the growth of granulation tissue and wound healing is a known concern (Dhall et al., 2015).

This suggests that the insulin effect on wound healing is related to its concentration. When the concentration is increased above a certain threshold, the effect is weakened, probably restraining normal wound healing speed. From this, it seems clear that a low-dose insulin can promote the regeneration of wound tissue (Zhang et al., 2007 and Zhang et al., 2011).

In conclusion, the local application of small dose of PRP in the site of long bone fracture results in higher cure rate, shorter healing duration, and less postoperative pain. insulin comes in the second place after PRP but it is clear that PRP products are very preferable than insulin product due to easy to have with low costs of production as, all we need autologous blood from the same animal species, aseptic syringe, collecting tube and centrifuge.

\section{REFERENCES}

Anitua, E.; Andía, I.; Sanchez, M.; Azofra, J.; del Mar Zalduendo, M. and de la Fuente, M. et al. (2005): Autologous preparations rich in growth factors promote proliferation and induce VEGF and HGF production by human tendon cells in culture. J Orthop Res; 23: 281-6.

Anitua, E.; Prado, R. and Troya, M. et al. (2016): Implementation of a more physiolog-ical plasma rich in growth factor (PRGF) protocol. Platelets.; 4:1-8.

Anitua, E.; Sánchez, M.; Nurden, A.T.; Nurden, P.; Orive, G. and Andia, I. (2006): New insights into and novel applications for platelet-rich fibrin therapies. Trends Biotechnol.; 24:227-34.

Bancroft, J.D. and Gamble, M. (2008): Theory and practice of histological techquines. 6th edition, North Hollywood, CA. USA.

Barnes, G.L.; Kostenuik, P.J.; Gerstenfeld, L.C. and Einhorn, T.A. (1999): Growth factor regulation of fracture repair. J. Bone Miner. Res. 14, 1805-1815.

Battegay, J. (1995): Angiogenesis: mechanistic insights, neovascular diseases, and therapeutic approaches. $J$ Mol Med. 1995;73:333-346.

Bolander, M.E. (1992): Regulation of fracture repair by growth factors. Proc Soc Exp Biol Med., 200: 165-170.

Bostrom, M.P. and Camacho, A.B. (1998): Potential role of BMP fracture healing. Cli. Orthop. Related Res. 355: 274-282.

Bouxsein, M.L.; Turek, T.J.; Blake, C.A.; Augusta, D.D.; Li, X.; Stevens, M. and Seehem, H.J. (2001): Recombinant human BMP-2 accelerates healing in rabbit ulnear osteotomy model. J. Bone Jt. Surgery, 83:1219-1230.

Castillo-Cardiel Guadalupe; Víctor Manuel Medina-Quintana; Mario Lomelí-Enríquez Fabiola Medrano-Muñoz; Celia GuerreroVelázquez; Carmen Karina Contreras-López Clotilde Fuentes-Orozco; Leire IrustetaJiménez; Luis Rodrigo Michel-Espinoza and Alejandro González-Ojeda (2017): Plateletrich plasma and its effect in bone regeneration in mandibular fractures. Controlled clinical trial. Gaceta Médica de México. 2017; 153.

Coetzee, J.C.; Pomeroy, G.C. and Watts, J.D. et al. (2005): The use of autologous concentrated growth factors to promote syndesmosis fusion in the Agility total ankle replacement. A preliminary study. Foot Ankle Int; 26:840846.

Creaney, L. and Hamilton, B. (2008): Growth factor delivery methods in the management of sports injuries: the state of play. Br J Sports Med;42:314-20.

Da-Wei Wang; Shun-Lei Du; Ming-Tao Xu; Yi-Ting Lu; Zhan-Chao Wang and Le-Xin Wang (2013): Effects of insulin therapy on fracture healing and expression of VEGF in diabetic rats. J Appl Biomed. 11: 33-40, 2013.

De Mos, M.; van der Windt, AE.; Jahr, H.; van Schie, HT.; Weinans, H. and Verhaar, JA. et al. (2008): Can platelet-rich plasma enhance tendon repair? A cell culture study. Am J Sports Med; 36:1171-8.

Dhall, S.; Silva, JP.; Liu, Y.; Hrynyk, M.; Garcia, M.; Chan, A.; Lyubovitsky, J.; Neufeld, RJ. and Martins-Green, M. (2015): Release of insulin from PLGA-alginate dressing stimulates regenerative healing of burn wounds in rats. Clin Sci (Lond) 129: 1115-1129.

Einhorn, T.A. and Gerstenfeld, L.C. (2015): Fracture healing: mechanisms and interventions Nat. Rev. Rheumatol. 11, 45-54.

Einhorn, T.A. (1995): Enhancement of fracturehealing. J. Bone Jt Surg., 77-A: 940-956. 
Einhorn, T.A. (1998): The cell and molecular biology of fracture healing. Clin. Orthop. (Suppl 355), S7-21.

Fathy, M.Z.; Ragab, G.H.; Seif, M.M.; Gadallah, S.M.; Salah Deeb and Nesreen $M$. Safwat (2018): Clinico-radiographic and histopathologic evaluation of iliac shaft fracture in dogs (An experimental study). Beni-Suef University Journal of Basic and Applied Sciences, 7(2): 165-170.

Foster, E.T.; Puskas, B.L.; B. R. Mandelbaum, M. B. Gerhardt and S. A. Rodeo (2009): Platelet Rich Plasma: From Basic Science to Clinical Applications. The American Journal of Sports Medicine. 3(11): 2259-2272.

Gandhi Ankur, Heather, A.; Beam, J.; Patrick O'Connor, J. and Russell Parsons, Sheldon S. Lin (2005): The effects of local insulin delivery on diabetic fracture healing. Bone 37 (2005) 482-490.

Gerstenfeld, L.C.; Cullinane, D.M.; Barnes, G.L.; Graves, D.T. and Einhorn, T.A. (2003): Fracture healing as a post-natal developmental process: molecular, spatial, and temporal aspects of its regulation. J. Cell. Biochem. 88, 873-884.

Ghaffarpasand Fariborz; Mostafa Shahrezaei and Maryam Dehghankhalili (2016): effects of Platelet Rich Plasma on Healing Rate of Long Bone Non-union Fractures: A Randomized Double-Blind Placebo Controlled Clinical Trial. Bull Emerg Trauma 2016; 4(3):134-140

Glowacki, J. (1998): Angiogenesis in fracture repair. Clin. Orthop. (Suppl 355), S82-S89.

Graves Dana, T.; Jazia Alblowi, David N.; Paglia, James Patrick O'Connor and Sheldon Lin (2011): Impact of Diabetes on Fracture Healing. REVIEW ARTICLE. Journal of Experimental and Clinical Medicine; 3(1):38.

Grundnes, O. and Reikeras, O. (1993): The importance of the hematoma for fracture healing in rats. Acta Orthop. Scand. 64, 340342.

Hadjiargyrou, M.; Lombardo, F.; Zhao, S.; Ahrens, W.; Joo, J.; Ahn, H.; Jurman, M.; White, D.W. and Rubin, C.T. (2002): Transcriptional profiling of bone regeneration. Insight into the molecular complexity of wound repair. $J$. Biol. Chem. 277, 30177-30182.

Hakimi, M1.; Jungbluth, P.; Sager, M.; Betsch, M.; Herten, M.; Becker, J.; Windolf, J. and Wild, M. (2010): Combined use of platelet-rich plasma and autologous bone grafts in the treatment of long bone defects in mini-pigs. Injury. 41(7):717-23.

Hammond, JW.; Hinton, RY.; Curl, LA.; Muriel, JM. and Lovering, RM. (2009): Use of autologous platelet-rich plasma to treat muscle strain injuries. Am J Sports Med; 37:1135-42.

Hanna, R.; Trejo, P.M. and Weltman, R.L. (2004): Treatment of intrabony defects with bovinederived xenograft alone and in combination with platelet-rich plasma: a randomized clinical trial. J Periodontol; 75:1668-1677.

Hauser, C.J.; Zhou, X.; Joshi, P.; Cuchens, MA.; Kregor, P.; Devidas, M.; Kennedy, RJ.; Poole, G.V. and Hughes, J.L. (1997): The immune microenvironment of human fracture/soft-tissue hematomas and its relationship to systemic immunity. J. Trauma 42, 895-903.

Hausman, M.R.; Schafflera, M.B. and Majeskaa, R.J. (2001): Prevention of fracture healing in rats by an inhibitor of angiogenesis. Bone 29: 560-564

Hee, H.T.; Majd, M.E.; Holt, R.T. and Myers, L. (2003): Do autologous growth factors enhance transforaminal lumbar interbody fusion? Eur Spine J; 12:400-407.

Jubb, K.V.F.; Kennedy, P.C. and Palmer, N. (2016): Pathology of domestic animals. 6th ed., Saunders, Elsevier, Pheladelphia.

Kalfas, H.I. (2001): Principles of bone healing. Neurosurg. Focus, 10 (4):1-4.

Kasten Philip; Julia Vogel; Florian Geiger; Philipp Niemeyer; Reto Luginbu" hl and Krisztian Szalay (2008): The effect of platelet-rich plasma on healing in critical-size long-bone defects. Biomaterials 29: 3983-3992.

Koskela von Sydow, A.; Janbaz, C.; Kardeby, C.; Repsilber, D. and Ivarsson, M. (2016): IL-1 $\alpha$ counteract TGF- $\beta$ regulated genes and pathways in human fbroblasts. $J$ Cell Biochem 117: 1622-1632.

Kryger, Z.B.; Sisco, M.; Roy, N.K.; Lu, L.; Rosenberg, D. and Mustoe, T.A. (2007): Temporal expression of the transforming growth factor-Beta pathway in the rabbit ear model of wound healing and scarring. $J A m$ Coll Surg 205: 78-88.

Lingen, M.W. (2001): Role of Leukocytes and Endothelial Cells in the Development of Angiogenesis in Inflammation and Wound Healing. Arch Pathol Lab Med-Vol 125.

Mandracchia, V.J. et al. (2001): Current concepts of bone healing. Clin. Podiatr. Med. Surg. 18, 55-77.

Ming, Z.; Yan, Z.; Wenjun, L.; Wei, Z. and Jinxiong, $X$. (2016): Clinical study on local application of low-dose insulin for promoting wound healing after operation for deep burns. Expeimental and therapeutic medicine 12: 3221-3226.

Mizuno, K.; Mineo, K.; Tachibana, T.; Sumi, M.; Matsubara, T. and Hirohata, K. (1990): The osteogenetic potential of fracture haematoma. Subperiosteal and intramuscular 
transplantation of the haematoma. J. Bone Joint Surg. Br. 72, 822-829.

Okuda, K1.; Tai, H.; Tanabe, K.; Suzuki, H.; Sato, T.; Kawase, T.; Saito, Y.; Wolff, LF. and Yoshiex, H. (2005): Platelet-rich plasma combined with a porous hydroxyapatite graft for the treatment of intrabony periodontal defects in humans: a comparative controlled clinical study. J Periodontol; 76:890-898.

Pocaterra, A.; Caruso, S. and Bernardi, S. et al. (2016): Effectiveness of platelet- rich plasma as an adjunctive material to bone graft: A systematic review and meta-analyisis of randomized controlled clinical trials. Int $J$ Oral Maxillo-fac Surg. 2016; 27:55-70.

Puddu, A.; Sanguineti, R.; Traverso, C.E.; Viviani, G.L. and Nicolò, M. (2016): Response to anti-VEGF-A treatment of endothelial cells in vitro. Exp Eye Res 146: 128-136.

Sanchez, A.R.; Sheridan, P.J.; Eckert, S.E. and Weaver, A.L. (2005): Regenerative potential of platelet-rich plasma added to xenogenic bone grafts in peri-implant defects: a histomorphometric analysis in dogs. $J$ Periodontol; 76:1637-1644.

Sánchez, M.; Anitua, E.; Azofra, J.; Andía, I.; Padilla, S. and Mujika, I. (2007): Comparison of surgically repaired Achilles tendon tears using platelet-rich fibrin matrices. Am J Sports Med; 35:245- 51.

Say, F.; Turkeli, E. and Bulbul, M. (2014): Is Platelet-Rich Plasma Injection an Effective Choice in Cases of Non-Union? ACTA CHIRURGIAE ORTHOPAEDICAE, 81, 340345.

Shantaram, S.K. (2016): Clinical evaluation of platelet rich plasma on fracture healing in capprine. M.V. Sc thesis Veterinary Surgery and radiology College of Veterinary and Animal Sciences, Parbhani. India

Shibata, Y.; Fujita, S.; Takahashi, H.; Yamaguchi, A. and Koji, T. (2000): Assessment of decalcifying protocols for detection of specific RNA by non-radioactive site hybridization in calcified tissue. Histochem. Cell Biol. 113, 153-159.

Street, J.; Street, J1.; Winter, D.; Wang, JH.; Wakai, A.; McGuinness, A. and Redmond, HP. (2000): Is human fracture hematoma inherently angiogenic? Clin. Orthop. 378, 224-237.

Street, J.T.; Wang a, J.H.; Wu, Q.D. and Wakai, A. (2001): The angiogenic response to skeletal injury is preserved in the elderly. J. Orthop. Res. 19, 1057-1066.

Thiede, M.A.; Smock, S.L.; Petersen, D.N.; Grasser, W.A.; Nishimoto, S.K. and Thoompson, D.D. (1993): Production of osteocalcin by platelets: a potentially important link of platelet action in bone ternover. J Bone Miner Res., 8:147-157.

Trueta, J. (1963): The role of the vessels in osteogenesis. J. Bone Jt Surg. Ser A. 45B, 402-418.

Wilkins, R.M.; Chimenti, B.T. and Rifkin, R.M. (2003): Percutane-ous treatment of long bone nonunions: the use of autologous bone marrow and allograft bone matrix. Orthopedics, 26: 549-554.

Wroblewski, A.P.; Melia, H. and Wright, V.J. (2010): Application of platelet rich plasma to enhance tissue repair. Oper Tech Orthop. 20:98-105.

Zhang, X.J.; Men,g C.; Chinkes, D.L. and Herndon, D.N. (2011): Benefcial 12 effects of insulin on cell proliferation and protein metabolism in skin donor site wound. J Surg Res 168: e155-e161.

Zhang, X.J.; Wu, X.; Wolf, S.E.; Hawkins, H.K.; Chinkes, D.L. and Wolfe, R.R. (2007): Local insulin-zinc injection accelerates skin donor site wound healing. J Surg Res 142: 90-96.

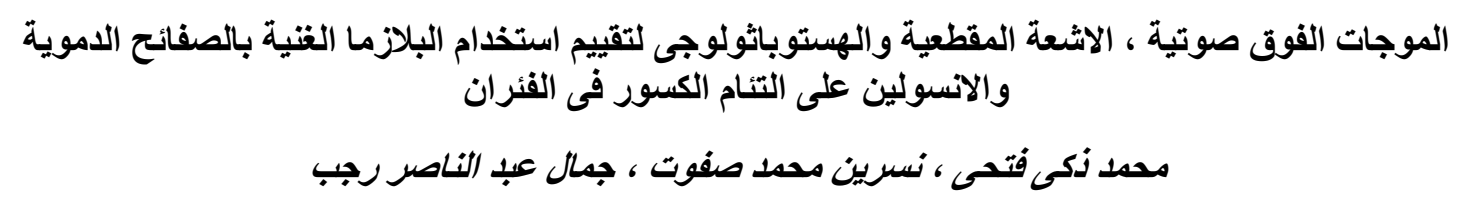

E-mail: mzfhussein83@gmail.com Assiut University web-site: www.aun.edu.eg

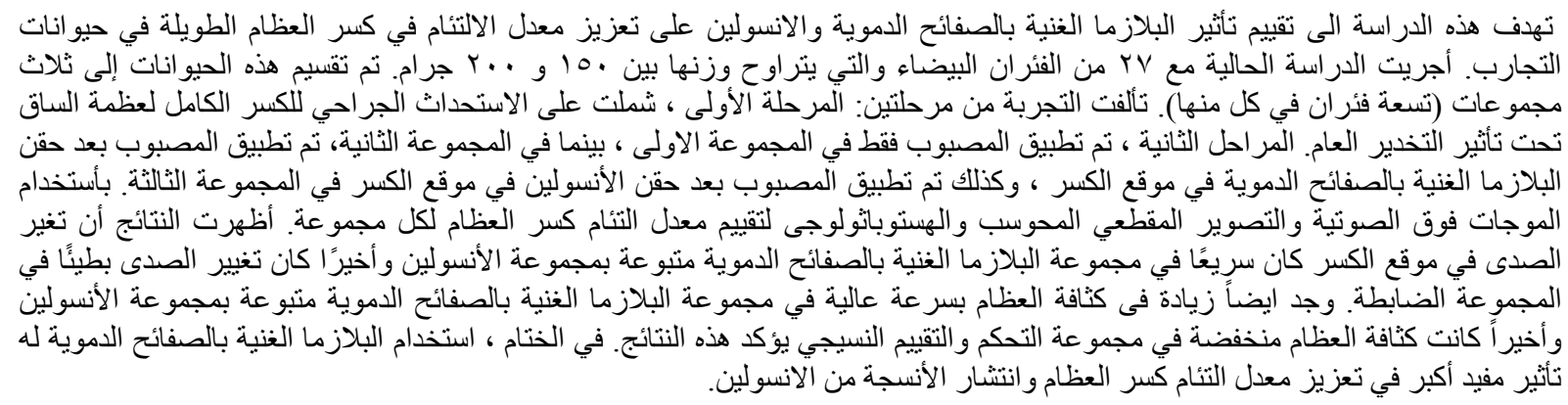

